\title{
TRAMPLE DAMAGE OF STONE FLAKES AS AN INDEX OF OCCUPATION INTENSITY: A CASE STUDY FROM MAGNIFICENT GALLERY
}

\author{
SILVANO JUNG
}

\begin{abstract}
A comparative index of trampling intensity was used in the analysis of the stone artefact assemblage at Magnificent Gallery (southeast Cape York Peninsula, Northern Queensland), to take into account the inter-related processes of flake breakage and sedimentation. This demonstrated a late decrease in the proportion of broken flakes, which largely reflected associated increases in sedimentation rates, rather than decreased occupational intensity. The analysis took into account the inverse relationship between sedimentation rate and frequency of flake breakage. The results indicate that people may have visited the site more frequently and/or for longer periods in the past 1,000 years.
\end{abstract}

\section{Introduction}

A number of archaeological site formation processes have observable mechanical effects, such as size reduction, sorting, vertical and horizontal movement of artefacts in the site matrix and artefact damage (Schiffer and McGuire 1982:255). Since some of these processes, such as damage of stone artefacts by trampling or 'cooking', result from human use of sites and vary according to relative intensity of use, they can be used as a quantitative measure of this intensity (e.g. Hiscock 1985; Mitchell 1988). Other possible indices of occupational intensity include numbers of stone implements discarded per unit time and rate of sediment accumulation (Hughes 1977). However, none of these possible measures for occupational intensity are straightforward; all can be explained in other ways. For instance, Hiscock (1981:32) has noted that changes in stone artefact discard rates could also reflect changes in stone knapping technology.

This paper examines rates of artefact discard, artefact damage and sediment accumulation in unison, as a way of demonstrating a late Holocene increase in occupational intensity at a rockshelter site.

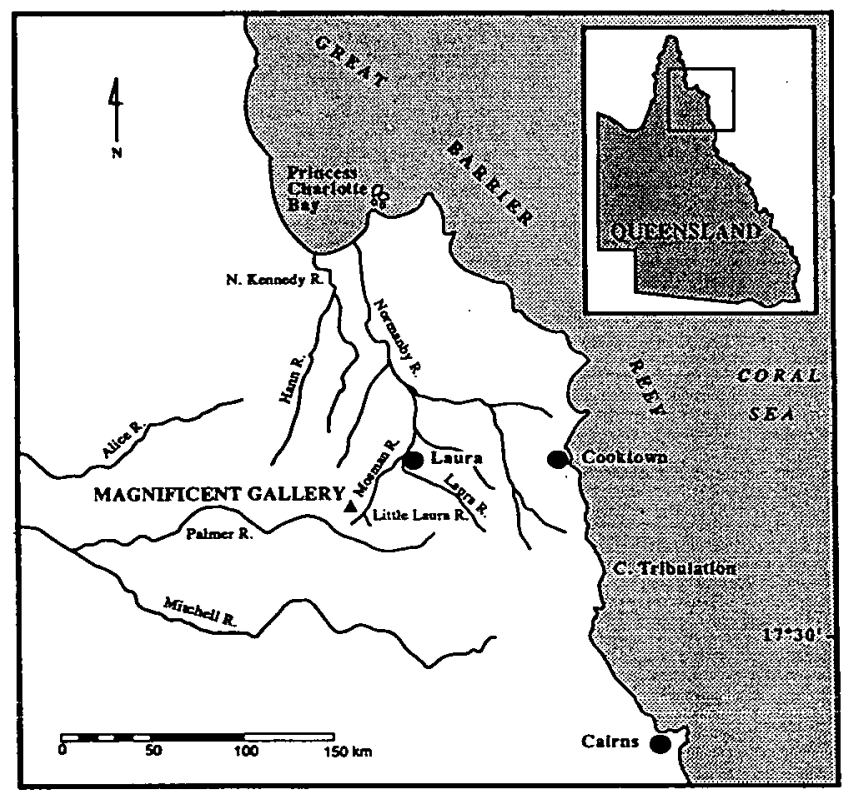

Figure 1: Location Map of Magnificent Gallery
The site selected for the study is Magnificent Gallery (southeast Cape York Peninsula, Northern Queensland), a sandstone rockshelter in an escarpment flanking Mosman Gorge in the Quinkan Reserves, $190 \mathrm{~km}$. northwest of Cairns (Figure 1). It was excavated in 1989 as part of a general investigation of the prehistory of the Laura-Cooktown region (see Morwood 1989; Jung 1990).

The excavation over an area measuring 3 by 1 metre, yielded 1997 stone artefacts, as well as ochreous nodules, bark, string, gum and faunal and floral remains. Three radiocarbon dates are available, with the lowermost suggesting initial site occupation of about 11,000 years ago.

\section{Trampling damage}

Transverse snapping of flakes was found to be the main type of breakage throughout the assemblage and this is commonly thought to result from trampling (Sutton 1985). Changes in the uppermost three stratigraphic layers (ie Spits 1-8), where the majority of the artefacts were found, are shown in Figure 2 (see Table 1 for total number of stone artefacts). This covers the last 6,200 years of the sequence. At a simple level of interpretation, the general reduction in the proportion of broken flakes over time would suggest a decrease in

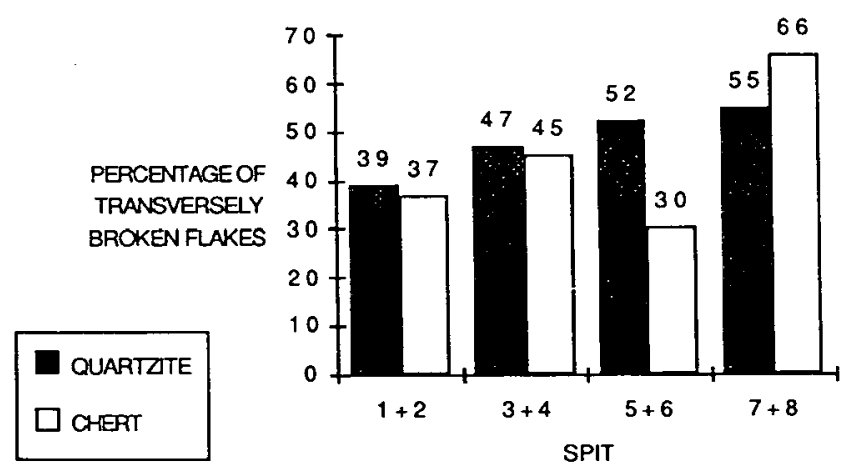

Figure 2: Percentage of transversely broken flakes per spit. Numbers above bars show raw frequencies. Oniy broken quartzite and chert flakes were analysed because the sample sizes for other raw material types were too small. 
occupational intensity. However, the situation is actually more complex because flake breakage rates are not merely determined by the intensity of site use, but also by the length of time stone flakes are exposed on the surface. Since the rate of deposit buildup is also likely to have varied in response to Aboriginal site use, this needs to be taken into account in calculating a trampling index.

\section{Rates of sedimentation and artefact discard}

At many sites the rate of sediment buildup and artefact discard seems proportional to the level of human activity (eg Hughes 1977; Jones and Johnson 1985). On the basis of the three radiocarbon dates, rates of sediment and artefact accumulation were estimated (Table 2). Figures 3 and 4 show that both sedimentation and artefact discard rates increased markedly throughout Layer 1 (Spits 1-4), at the same time as the reduction in the proportion of transversely snapped flakes might superficially suggest a decrease in occupational intensity. This apparent inconsistency between rates (of occupation intensity based on flake breakage and rates of sediment/artefact accumulation), is explicable in terms of the negative correlation between length of artefact exposure and degree of trample damage. In turn, length of artefact exposure is inversely proportional to the rate of sediment accumulation. This can be accounted for in the following way:

The proportion of broken flakes $(\mathrm{Fb})$ is directly proportional to the amount of trampling ( $T$ ), but inversely proportional to the rate of sedimentation (S) so:

\section{$\% \mathbf{F b} \propto \mathrm{T} / \mathrm{S}$}

A more realistic trampling index can, therefore, be calculated as:

$$
\mathbf{T} \propto \mathbf{F b} \times \mathbf{S}
$$

On the basis of three radiocarbon dates, sedimentation rates at Magnificent Gallery were calculated as:

$$
\begin{array}{lll}
0-11 \mathrm{~cm} . & = & 10.4 \mathrm{~cm} / 1000 \text { years } \\
11-22.5 \mathrm{~cm} . & = & 1.9 \mathrm{~cm} / 1000 \text { years } \\
22.5-35 \mathrm{~cm} . & = & 3.0 \mathrm{~cm} / 1000 \text { years }
\end{array}
$$

(Artificially inflated because of the narrow area of concentration)

These results were then used to calculate a composite occupation intensity index as above. The results are evident in Table 3 which summarises indices for quartzite and chert flakes for Layers 1,2 and 3 (the sample size was insufficient to include Layer 4). This indicates that, in the context of an associated increase in sedimentation, the degree of trampling increased in layers which had higher concentration of artefacts. Trampling intensity was higher in Layer 1 (for both quartzite and chert) than in Layers 2 and 3.

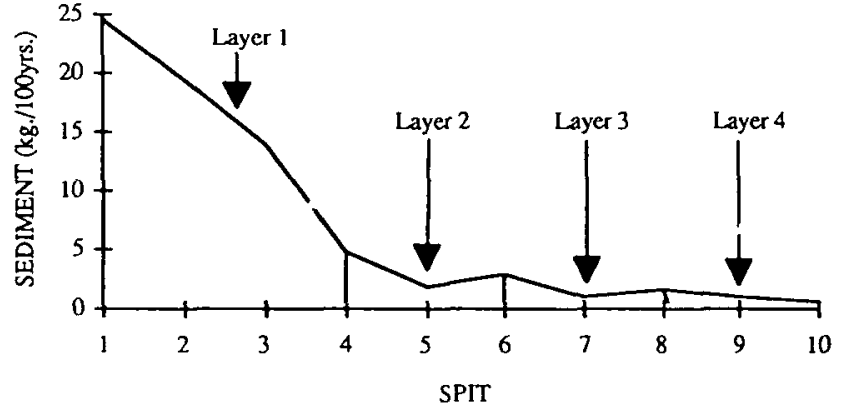

Figure 3: Rate of sedimentation (kilograms per 100 years).

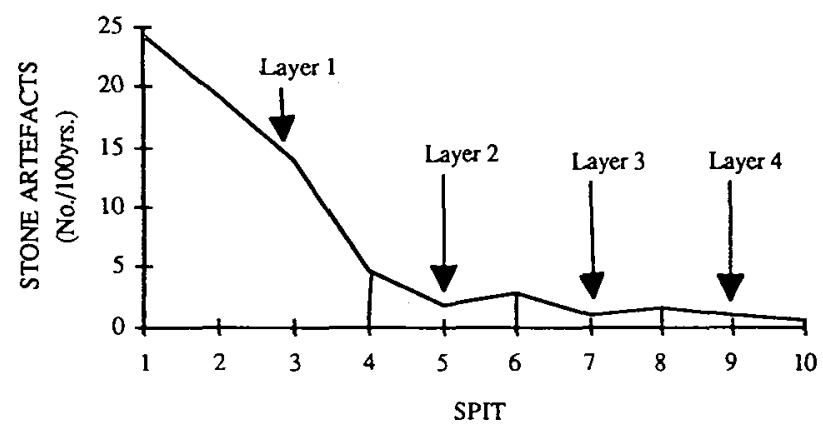

Figure 4: Stone artefacts (number per 100 years).

\section{Conclusion}

A complex of factors demonstrates that occupational intensity at Magnificent Gallery increased significantly in the last 1,000 years. This has implications for the general prehistory of southeast Cape York Peninsula, especially when considered in light of similar developments during the late Holocene at other sites in the region (David 1991). This study also emphasizes that if the degree of trampling damage is to be used as a measure of occupational intensity, associated changes

\begin{tabular}{|c|c|c|c|c|c|c|c|}
\hline & SPTT & FLAKES & FLAKED PIECES & CORES & GRIND ST. FRAG. & BURRENS & TOTAL \\
\hline \multirow[t]{4}{*}{ LAYER I } & 1 & 163 & 247 & 3 & 2 & 3 & $\overline{418}$ \\
\hline & 2 & 199 & 257 & $t$ & 1 & 3 & 461 \\
\hline & 3 & 104 & 168 & 0 & 2 & $\mathbf{0}$ & 274 \\
\hline & 4 & 69 & 136 & 0 & $\mathrm{I}$ & 2 & 208 \\
\hline LAYER 2 & 5 & 68 & 127 & $\bar{I}$ & $T$ & $\overline{0}$ & 197 \\
\hline \multirow[t]{3}{*}{ LAYER 3} & 6 & $\overline{84}$ & 118 & 3 & $\overline{0}$ & 0 & 205 \\
\hline & 7 & 62 & 31 & 3 & 1 & 0 & 97 \\
\hline & 8 & 34 & 17 & 1 & 0 & 0 & 52 \\
\hline \multirow[t]{5}{*}{ LAYFR 4} & 9 & $\overline{28}$ & 22 & $\overline{0}$ & 0 & $\overline{0}$ & 50 \\
\hline & 10 & 19 & 5 & 0 & 0 & 0 & 24 \\
\hline & 11 & 1 & 7 & 0 & $\mathbf{0}$ & 0 & 8 \\
\hline & 12 & 1 & 0 & 0 & 0 & 0 & 1 \\
\hline & 13 & 0 & 2 & 0 & 0 & 0 & 2 \\
\hline \multirow[t]{4}{*}{ LAYER 5} & 14 & 1 & 0 & 0 & 0 & $\overline{0}$ & 1 \\
\hline & 15 & 0 & 0 & 0 & 0 & 0 & 0 \\
\hline & 16 & 0 & $\mathbf{0}$ & 0 & 0 & 0 & 0 \\
\hline & 17 & 0 & 0 & 0 & 0 & 0 & 0 \\
\hline TOTAL & & 832 & 1137 & 12 & $\overline{8}$ & 8 & 1997 \\
\hline
\end{tabular}
in sediment buildup must be taken into account.

Table 1: Total number of stone artefacts at Magnificent Gallery 
Table 2: Magnificent Gallery: age and contents of spits with occupation

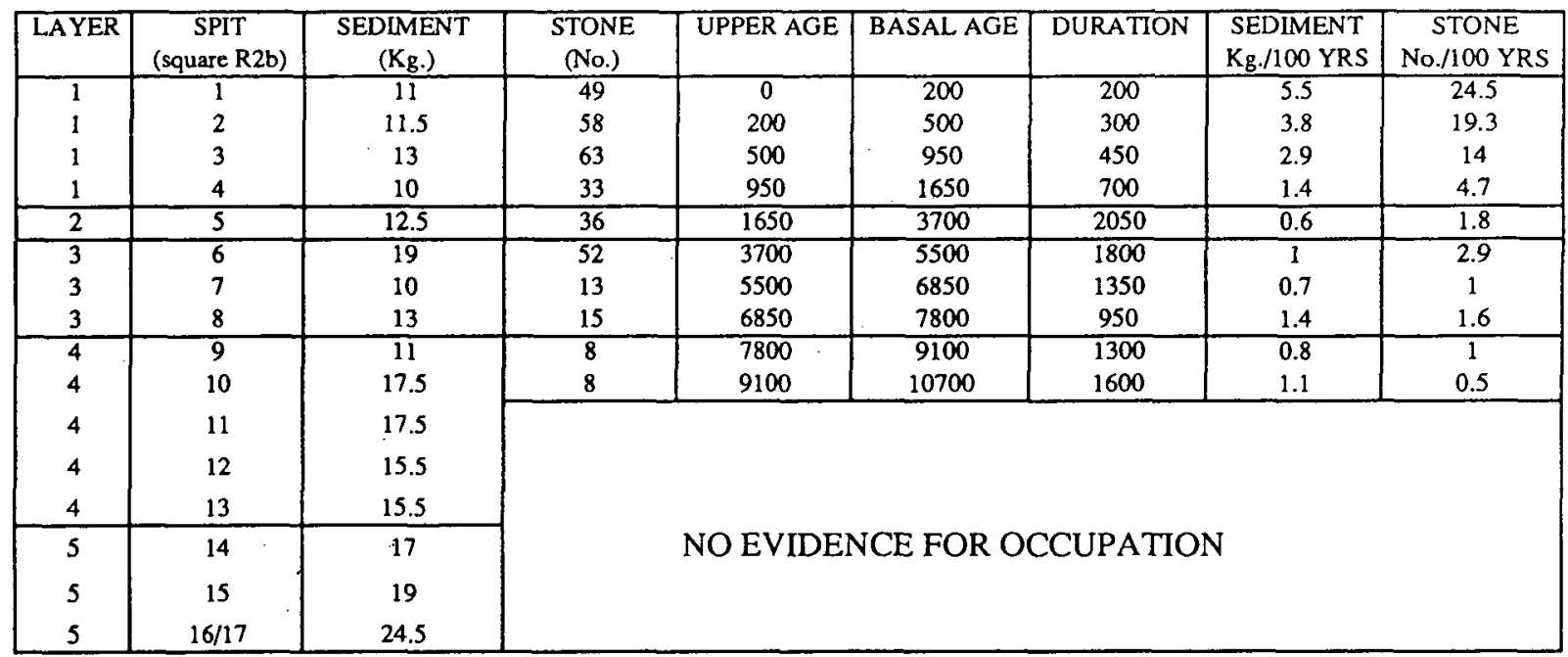

Table 3: Comparative index for trampling intensity.

\begin{tabular}{c|c|c|c|c}
\hline LAYER & SPIT & $\begin{array}{c}\text { RAW } \\
\text { MATERIAL }\end{array}$ & $\begin{array}{c}\text { \% BROKEN FLAKES X SED. } \\
\text { RATE }\end{array}$ & VALUE \\
\hline 1 & $1-2$ & QUARTZTE & $39 \times 10.4$ & 405.6 \\
1 & $3-4$ & QUARTZITE & $47 \times 10.4$ & 488.8 \\
\hline 2 and 3 & $5-6$ & QUARTZTE & $52 \times 1.9$ & 98.8 \\
\hline 3 & $7-8$ & QUARTZTTE & $55 \times 1.9$ & 104.5 \\
\hline 1 & 1.2 & CHERT & $37 \times 10.4$ & 384.8 \\
1 & $3-4$ & CHERT & $45 \times 10.4$ & 468 \\
\hline 2 and 3 & $5-6$ & CHERT & $30 \times 1.9$ & 57 \\
\hline 3 & $7-8$ & CHERT & $66 \times 1.9$ & 125.4 \\
\hline
\end{tabular}

\section{Acknowledgments}

The data from Magnificent Gallery was collected by Mike Morwood in 1989 as part of a three year excavation program in Cape York Peninsula. I wish to thank Mike for the opportunity to work with him in the field, as well as for his helpful proof reading and useful suggestions in this paper. Thanks Doug Hobbs for help with computing.

\section{References Cited}

David, B. 1991 Fern Cave, rock art and social formations: rock art regionalisation and demographic models in southeastern Cape York Peninsula. Archaeology in Oceania. Vol. 26, No. 2, July: 41-57.

Hiscock, P. 1981 Comments on the use of chipped stone artefacts as a measure of 'intensity of site usage'. A ustralian A rchaeology. December: 30-34.

Hiscock, P. 1985 The need for a taphonomic perspective in stone artefact analysis. Queensland A rchaeological Research. Vol. 2: 82-97.

Hughes, P. 1977 A geomorphological interpretation of selected archaeological sites in southern coastal New South Wales. Unpublished Ph.D. Thesis, University of New South Wales.

Jones, R. and I. Johnson. 1985 Deaf Adder Gorge: Lindner Site, Nauwalabila 1. In R. Jones (ed.) 1985. A rchaeological Research in Kakadu National Park. Australian National Parks and Wildlife Service, Special Publication No. 13: 165-224.
Jung, S. 1990 Chronological changes in stone artefact resource utilisation at Magnificent Gallery: southeastern Cape York Peninsula, Northern Queensland. Unpublished (M. Litt.) Thesis, University of New England, Armidale NSW.

Mitchell, S. 1988 Chronological change in intensity of site use at Seal Point: a technological analysis. Vol. 1. Unpublished B.A. (Hons.) Thesis. University of Queensland.

Morwood, M. 1989 The archaeology of Aboriginal art in southeast Cape York: a research proposal. Rock Art Research. 6:71-72.

Schiffer, M.B. and R.H. McGuire. 1982 The study of cultural adaptation. In R.H. McGuire and M.B. Schiffer (eds), Hohokam and Patayan. Prehistory of Southwestem Arizona. New York, Academic Press: 223-274.

Sutton, S. 1985 Warragarra Stone. Unpublished (Hons.) Thesis, University of New England. Armidale NSW. 